\title{
Oesophageal obstruction and ulceration caused by oral potassium therapy
}

\author{
James Pemberton \\ From the Department of Thoracic Surgery, St. Bartholomew's Hospital, London E.C.I
}

$A$ case is described of oesophageal ulceration and hold up following oral potassium therapy. The patient had recently undergone mitral valve replacement.

For the treatment of patients in severe cardiac failure, large oral doses of potassium supplements are required to replace the potassium-wasting effect of diuretic. The ideal potassium preparation has not yet been found. For maximum utilization of the potassium, Kassirer et al. (1965) emphasize that it should be given as the chloride salt, but the ulcerating effect of potassium chloride on the small intestine has been widely recognized (Allen et al., 1965; Boley et al., 1965; Morgenstern, Freilich, and Panish, 1965). 'Slow K' (Ciba) has been claimed to overcome this difficulty, and as yet no reports of gastro-intestinal ulceration in man have been seen following its use. In this report, we present a patient who has suffered oesophageal ulceration following therapy with 'Slow K', and we suggest that under certain circumstances this will cause such damage: thus it seems important to recognize patients with oesophageal stasis; in such patients an alternative way of giving oral potassium supplements is desirable.

\section{Case report}

A 44-year-old woman had a long-standing history of rheumatic valve disease: mitral valvotomy had been performed in 1953 and a second reconstruction operation on the mitral and tricuspid valves was carried out under cardiopulmonary bypass in 1962. Severe disability and gross cardiac enlargement persisted despite therapy with frusemide 80 mg. b.d., 'Slow K' 1200 mg. t.d.s., spironolactone $25 \mathrm{mg}$. t.d.s., and digoxin 0.25 mg. b.d. In March 1969, the mitral valve was replaced with a No. 2 Starr-Edwards valve. For the first week after operation, she required artificial ventilation, and her drug regimen was continued by giving intravenous potassium chloride and intramuscular digoxin and frusemide.
Two days after resuming oral therapy with digoxin $0.25 \mathrm{mg}$., frusemide $40 \mathrm{mg}$. b.d., and 'Slow K' $1200 \mathrm{mg}$. q.d.s., she complained of difficulty in swallowing one of the 'large yellow tablets' which she said she could feel sticking in her chest. This feeling persisted and severe retrosternal pain ensued. The dysphagia and pain were so intense after taking her tablets the following morning that an emergency barium swallow was carried out.

The barium swallow (Fig. I) showed a persistent filling defect in the lower third of the oesophagus just above the cardiac impression. The defect had the appearance of an impacted tablet and barium was seen to flow readily past it.

Oesophagoscopy, some five hours later, showed an area of mucosal ulceration on the posterior wall of the lower third of the oesophagus filled with and surrounded by white powder. There was intense spasm below the ulcerated area. Oesophageal lavage was carried out. A naso-gastric tube was inserted and feeding was entirely by tube for the next five days. No further 'Slow K' was given and potassium supplement as effervescent B.P.C. was substituted. The patient's dysphagia resolved and before discharge a repeat barium swallow showed only the atrial impression at the lower end of the oesophagus: there was no evidence of stricture or ulceration.

\section{Discussion}

Potassium supplements are usually necessary when a patient with heart disease is being treated with diuretics. There is strong evidence that potassium should be given as the chloride salt (Kassirer et al., 1965), for chloride is required for the optimal absorption and utilization of the potassium ions. Preparations such as effervescent potassium B.P.C. that contain no chloride are undesirable despite their palatability, and potassium chloride in solution cannot be tolerated by many patients. Tablets of potassium chloride 


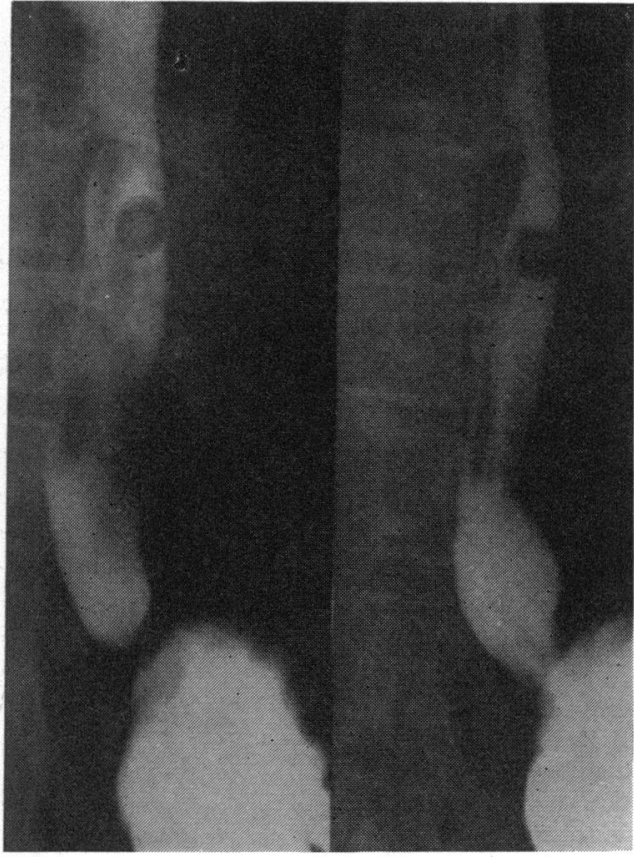

FIG. I Barium swallow on both views. There is a round filling defect in the lower third of the oesophagus, caused by the impacted potassium tablet.

FIG. 2 Lateral $\mathrm{x}$-ray of the chest with barium swallow, showing gross posterior displacement of the oesophagus by an enlarged left atrium.

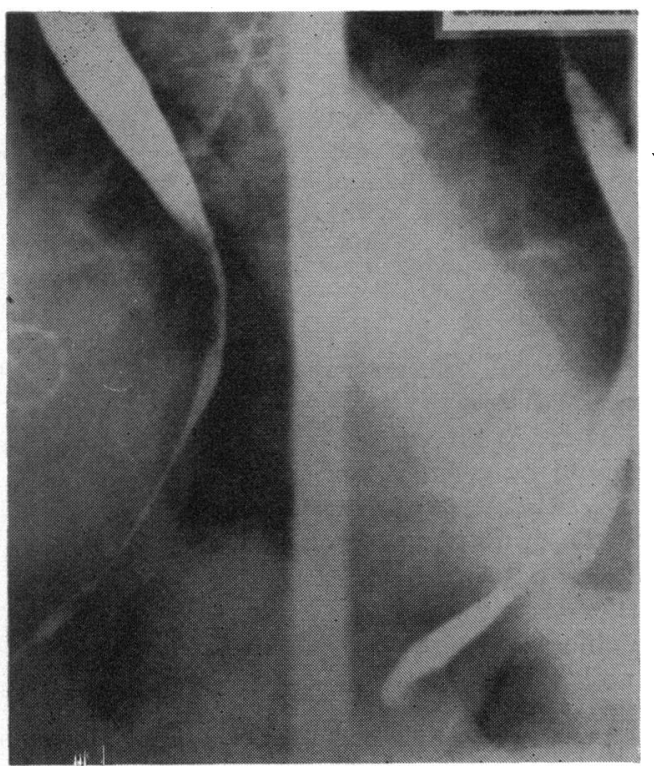

are subject to erratic absorption in the small intestine and many reports have indicated that there is a substantial risk of small bowel ulceration and stricture.

Attempts to devise a palatable, safe preparation of potassium chloride were made by producing an enteric-coated tablet. Unfortunately, these also produce small bowel lesions (Boley et al., 1965; Lindholmer and Räf, I965).

The combination of potassium chloride with a slow release core, 'Slow K', has done much to overcome the dangers of potassium therapy and no cases of ulceration of the gastro-intestinal tract have been reported until now. The patient described here, however, provided visible evidence of oesophageal ulceration in association with slow release potassium. The probable sequence of events was that the tablets were held up in the oesophagus at the level of the large left atrium (Fig. 2), and the continued action of the preparation on one localized area of mucosa over a period of $\mathbf{4 8}$ hours produced ulceration. The finding at oesophagoscopy of an ulcerated area with powder in and around it is strong evidence implicating the potassium salt as the causative agent.

Therapy with slow release potassium in the form of 'Slow $K$ ' has been remarkably trouble-free but the present case gives a warning that in circumstances predisposing to oesophageal stasis, ulceration may be produced. Fortunately, the patient's ulceration was detected before grave damage resulted. The patient is now taking effervescent potassium and has no symptoms to suggest residual ulceration or stenosis.

I wish to thank Mr. O. S. Tubbs and Dr. J. Hamer for permission to study their patient; and Dr. J. Fleming for his help and interest.

\section{References}

Allen, A. C., Boley, S. J., Schultz, L., and Schwartz, S. (1965). Potassium induced lesions of the small bowel. II. Pathology and pathogenesis. Fournal of the American Medical Association, 193, 1001.

Boley, S. J., Allen, A. C., Schultz, L., and Schwartz, S. (1965). Potassium-induced lesions of the small bowel. I. Clinical aspects. Fournal of the American Medical Association, 193, 997.

Kassirer, J. P., Berkman, P. M., Lawrenz, D. R., and Schwartz, W. B. (1965). The critical role of chloride in the correction of hypokalemic alkalosis in man. American fournal of Medicine, 38, 172.

Lindholmer, B., and Räf, L. (1965). Non-specific stenosing ulceration of the small intestine. Acta Chirurgica Scandinavica, 129, 434.

Morgenstern, L., Freilich, M., and Panish, J. F. (1965). The circumferential small-bowel ulcer. fournal of the American Medical Association, 191, 637. 